\title{
Una retrospectiva crítica de la obra cinematográfica de Lourdes Portillo
}

\section{A Critical Retrospective of Lourdes Portillo's Work}

\author{
Rosa Linda Fregoso \\ Universidad de California, Santa Cruz \\ rfregoso@ucsc.edu
}

\begin{abstract}
Resumen Esta retrospectiva crítica analiza la obra cinematográfica de la directora latina, Lourdes Portillo, empezando con su primer film de cortometraje, Después del terremoto (1979), codirigido por Nina Serrano hasta uno de sus más recientes documentales, Señorita Extraviada, (2001). Las películas de Lourdes Portillo plantean una serie de aspectos pertinentes para el feminismo descolonial/poscolonial y son emblemáticas del amplio espectro de las preocupaciones sociales, culturales y políticas de las artistas feministas y latinas. En todas sus obras, Portillo adopta una amplia visión transnacional, colocando a la mujer en el centro de sus historias y documentando las políticas económicas neoliberales, el legado de violencia de los regímenes militares, así como el vínculo de la violencia de género con las estructuras de dominación en la vida cotidiana de las mujeres.
\end{abstract}

Palabras clave Lourdes Portillo, Documental, Feminismo.

Abstract This critical retrospective analyzes the cinematic works of Latina director, Lourdes Portillo, starting with her first short film, After the Earthquake, 1979 (co-directed with Nina Serrano) to one of her most recent documentaries, Señorita Extraviada (2001). Lourdes Portillo's films raise pertinent issues for decolonial and postcolonial feminism, as much as they are emblematic of a wide spectrum of social, cultural and political concerns of Latina feminist artists. In her films, Portillo adopts a broad transnational vision that positions women at the center of the narrative, and documents the neoliberal economic policies, the legacy of military dictatorships, as well as the articulation of gender-based violence with structures of domination in the everyday lives of women.

Keywords Lourdes Portillo, Documentary, Feminism. 


\section{Introducción}

Esta retrospectiva crítica analiza la obra cinematográfica de Lourdes Portillo en una época de muchas contradicciones y en un tiempo especialmente difícil para el cine no comercial. En el caso de los Estados Unidos han disminuido los apoyos al sector público lo que ha afectado la obtención de recursos para estas producciones, de tal forma que la situación económica es más crítica hoy en día que en los años setenta, cuando Portillo inició su carrera como cineasta. Sin embargo, a pesar de los recortes de los fondos públicos para las áreas artísticas, el número de mujeres cineastas latinas en los Estados Unidos ha crecido. Este aumento está vinculado a la expansión de los circuitos de festivales internacionales, a la creación de formas alternativas de distribución y exhibición de los trabajos independientes, y al crecimiento en la demanda de materiales críticos e innovadores, en cine y video hechos por mujeres.

"El arte del cine puede ser utilizado al servicio de las desprotegidas", Lourdes Portillo escribió una vez en un artículo sobre Señorita Extraviada. "Y el documental puede adoptar una postura e informar, activar, promover el entendimiento y la compasión" (2003:234). Como su muy aclamado documental, Señorita Extraviada, las películas de Portillo están impulsadas por lo que Fernando Birri llama "una poética de la transformación de la realidad" pues sus obras representan unos de los mejores ejemplos del cine que "se propone modificar la realidad sobre la cual se proyecta” (1997: 96). Sus películas y videos son emblemáticos del amplio espectro de las preocupaciones sociales, culturales y políticas de las artistas feministas y latinas. Este ensayo se inspira tanto en el reconocimiento de las formas fundamentales en los que estos materiales contribuyen al proyecto de la "poética de la transformación de la realidad” como en las palabras de Juhasz quien revalora la importancia del realismo en los documentales políticos. Como señala Juhasz, nuestro contexto histórico demanda que las educadoras feministas analicemos y revaluemos el legado teórico del trabajo político feminista:

Cuando las mujeres están reinventando la rueda del feminismo para pelear todavía por nuestro derecho a los cuidados de salud y la libertad reproductiva, es crucial que las educadoras feministas en el cine y otros campos, vean y muestren de forma realista el cómo las mujeres abordamos el trabajo político de manera más similar que en la generación anterior (1994: 173).

Las películas de Lourdes Portillo plantean una serie de aspectos pertinentes para el feminismo descolonial/poscolonial. Nacida en Chihuahua, pero habiendo vivido su juventud y su vida adulta en el norte de California, Portillo es una cineasta latina cuyo trabajo hace referencia ha una amplia gama de temas que van desde la política de género hasta la cultura, desde la represión del Estado hasta el SIDA y el 
feminicidio en la zona fronteriza de México y los Estados Unidos. Se trata de una documentalista aclamada internacionalmente que trabaja en las fronteras entre dos o más culturas y entre varias tradiciones cinematográficas. A lo largo de más de treinta años, Portillo ha documentado la realidad, la cultura y la perspectiva de personas que generalmente han sido ignoradas o mal interpretadas en los medios de comunicación dominantes. Portillo comenzó su trabajo en la cumbre del debate feminista alrededor del documental realista frente al avant garde o las teorías de cine. Fue miembro del colectivo marxista llamado "Cine Manifest", en los años setenta Portillo se graduó en el Instituto de Artes de San Francisco. Como su trabajo lo ilustra, Portillo se siente influida por el cine latinoamericano, particularmente por el denominado Nuevo Cine Latinoamericano. Deliberadamente decide trabajar con el documental pero buscando incorporar formas innovadoras y experimentando con los géneros realista y político.

Ha finales de la década de los setenta Portillo realizó su primer film titulado Después del terremoto (After the Earthquake, 1979) que fue codirigido por Nina Serrano. Se trata de un delicado y sincero retrato de una trabajadora doméstica que migra de Nicaragua a California. Después del terremoto fue premiado con el "Diploma de honor" en el Festival Internacional de Cine de Cracovia-Polonia. Años más tarde, Portillo viaja a Argentina y junto con Susana Muñoz trabajan con las madres de los desaparecidos quienes desafían al régimen militar. La cinta de Portillo y Muñoz, Las Madres: The Mothers of the Plaza de Mayo (1986), jugo un rol importante en la difusión internacional de las condiciones de las madres de los desaparecidos en aquel país. Esta película fue nominada para un premio de la Academia en 1986. Con el documental La Ofrenda: Days of the Dead (1988), cambio de interés hacia el campo de las prácticas culturales, documentando la celebración del día de muertos en México, así como su recuperación y revitalización por parte de las chicanas y chicanos en Estados Unidos. En 1992, Portillo colaboró con el trío cómico, Culture Clash para producir el video experimental, Columbus on Trial (Colón a juicio, o El juicio de Colón) para la conmemoración internacional del viaje de Colón a las Américas. Uniéndose a los grupos indígenas en la protesta contra la celebración del Quinto Centenario y a la noción de Colón como el "descubridor", el video de Portillo reescribe el "descubrimiento" como una "conquista" y de manera humorística pone a Colón en el banquillo de los acusados de una sala de tribunal de hoy en día. Después, en El diablo nunca duerme (The Devil Never Sleeps, 1994), Portillo vuelve sus preocupaciones hacia la esfera doméstica. La investigación sobre la muerte de su Tío Oscar, sirve de telón de fondo para que la cineasta explora las dinámicas de las familias mexicanas. Además Portillo ha ampliado sus preguntas sobre la familia al enfocarse a la muerte $y$ leyenda de la cantante texana Selena, tejiendo la historia a partir del significado que para ella tenían: sus seguidores, el cuerpo y el patriarcado, en Corpus: a Home 
movie for Selena (1999). Su documental, Señorita Extraviada (2001) es uno de los primeros que investiga el feminicidio en la ciudad fronteriza de Ciudad Juárez Chihuahua. En todas sus obras, Portillo adopta una amplia visión transnacional, colocando a la mujer en el centro de sus historias y documentando los efectos de los procesos de globalización económica y política, así como el vínculo con las estructuras de dominación en la vida cotidiana de las mujeres.

\section{La migración laboral racial y el patriarcado latino}

El cortometraje de ficción en blanco y negro, Después del terremoto, trata sobre los conflictos que enfrenta una trabajadora migrante latina para definir su propia autonomía e independencia del patriarcado. La película documenta la "identidad en proceso” de Irene, la protagonista, así como su toma de conciencia de género. Ella es una trabajadora doméstica en una lujosa residencia de San Francisco, y anticipa, con alguna ambivalencia, los conflictos que se desataran al reunirse con Roberto, su novio de Nicaragua quien, después del terremoto de 1976, es puesto en libertad. Roberto es un activista político que fue preso por oponerse a la dictadura militar de Anastasio Somoza, es un revolucionario de izquierda, pero también un hombre latino tradicional que se siente amenazado por la independencia social y económica que ha logrado Irene. En este primer film, la realizadora explora la subjetividad e identidad de la mujer latina que se ve afectada por la migración laboral racial y el patriarcado latino.

Codirigido por Nina Serrano, el corto Después del terremoto, fue hecho dentro del contexto general de las políticas antimperialistas del Tercer Mundo y de las batallas específicas por la emancipación de la diáspora nicaragüense y de los movimientos de solidaridad de los setenta. Sin embargo, Portillo y Serrano se rehusaron a construir la típica narrativa de la emancipación centrada exclusivamente alrededor de la identidad política ya que se dieron cuenta que de esta forma se negaba el tratamiento y conocimiento de la multiplicidad de formas de dominación dentro de la estructura social. Consternadas por el exilio de los nicaragüenses que viven en San Francisco, Portillo y Serrano escriben una historia que se centra en el impacto de los procesos y de las relaciones patriarcales de género, de la migración laboral y de la dislocación cultural de la identidad y subjetividad de una trabajadora migrante latina. Como explicó Portillo en una entrevista con Kathleen Newman y B. Ruby Rich:

Estaba involucrada en el movimiento sandinista en los Estados Unidos, en los setenta, en solidaridad con ellos, junto con Nina Serrano quien codirigió esta película. Decidimos hacer un film que informara a la gente sobre la lucha ... y sobre los conflictos que los inmigrantes y nicaragüenses estaban viviendo en ese momento. No quería hacer una película que fuera el clásico documental serio, duro y lleno de datos. Vi la riqueza de sus vidas y quise 
capturarlas. Al mismo tiempo, cuando hice eso enfrenté una batalla contra (los sandinistas). Ellos en el proceso nos rechazaron porque ... querían que hiciéramos el típico documental que estaban acostumbrados a ver - con datos, politizado, y desde un sólo punto de vista-. Pero nosotras teníamos una beca del AFI, así que pense que si esta era mi película, y si yo tenía el control, podía hacer lo que yo quería. (Newman y Rich, 1990: 50-1).

En Después del terremoto, la narrativa de oposición radical y de política antiimperialista del movimiento de solidaridad nicaragüense aparece como una subtrama. La trama principal busca ubicar a la inmigrante latina en medio del lenguaje y la cultura, y en medio, también, de la dominación patriarcal, el capitalismo y el imperialismo.

Portillo y Serrano montan una coreografía del deseo de liberación de la protagonista dentro de la tensión entre el espacio interno y externo, de la esfera doméstica de la cultura tradicional y de la esfera pública de la producción (Fregoso, 1993). Después del terremoto se centra en una trabajadora doméstica que migra de Nicaragua a Estados Unidos y con ello se tocan dos amplios temas: la composición racial de la fuerza de trabajo, y la feminización de la migración laboral transnacional. $\mathrm{Al}$ retratar la vida ordinaria de una trabajadora domestica migrante, el film anticipa lo más novedosos de la investigación feminista.

Las investigadoras feministas han afirmado por mucho tiempo que el capital industrial creó una división estructural entre la "economía capitalista orientada a la ganancia” y la "vida doméstica". Esta división entre la producción y consumo, normalmente llamado la división público-privado, llevó al nacimiento de la categoría de "ama de casa" y a una redefinición de las mujeres como "guardianes del hogar y de lo doméstico". Sin embargo, la "domesticidad" no era una "condición universal" de todas las mujeres, pero estaba en cambio muy arraigada a las condiciones sociales de las clases medias y altas estadounidence, en los siglos diecinueve y veinte. Al igual que la experiencia de los ex-esclavos, las mujeres inmigrante y de otras minorías, han hecho evidente que ellas son primero trabajadoras asalariadas y en segundo lugar, amas de casa. En esta arena social, Después del terremoto capta la división racial entre trabajo doméstico no pagado y trabajo doméstico pagado. ${ }^{1}$

Irene es una mujer que trabaja fuera del hogar, es una latina que se mueve entre culturas e idiomas distintos, que se mueve entre la esfera pública y la privada teniendo la habilidad de actuar en múltiples niveles. Como latina inmigrante que vive en Estados Unidos, Irene opera en la esfera pública, laborando como trabajadora doméstica dentro de la economía del capitalismo avanzado. Ella obtiene

1 Ver Davis (1993); Romero (1992); y Nakano Glenn (1983). 
un ingreso al realizar una actividad productiva fuera de su propia casa pero dentro de la esfera doméstica y privada de otra casa. Y mientras que en la sociedad norteamericana, por lo menos a nivel ideológico, hay una separación del trabajo y la familia, como esferas separadas, según Mary Romero, y dado la naturaleza del trabajo involucrado, las chicanas y las trabajadoras domésticas latinas niegan la separación entre el trabajo y familia y perciben una distinción mínima entre las esferas del trabajo casero (homemaking) y el trabajo doméstico².

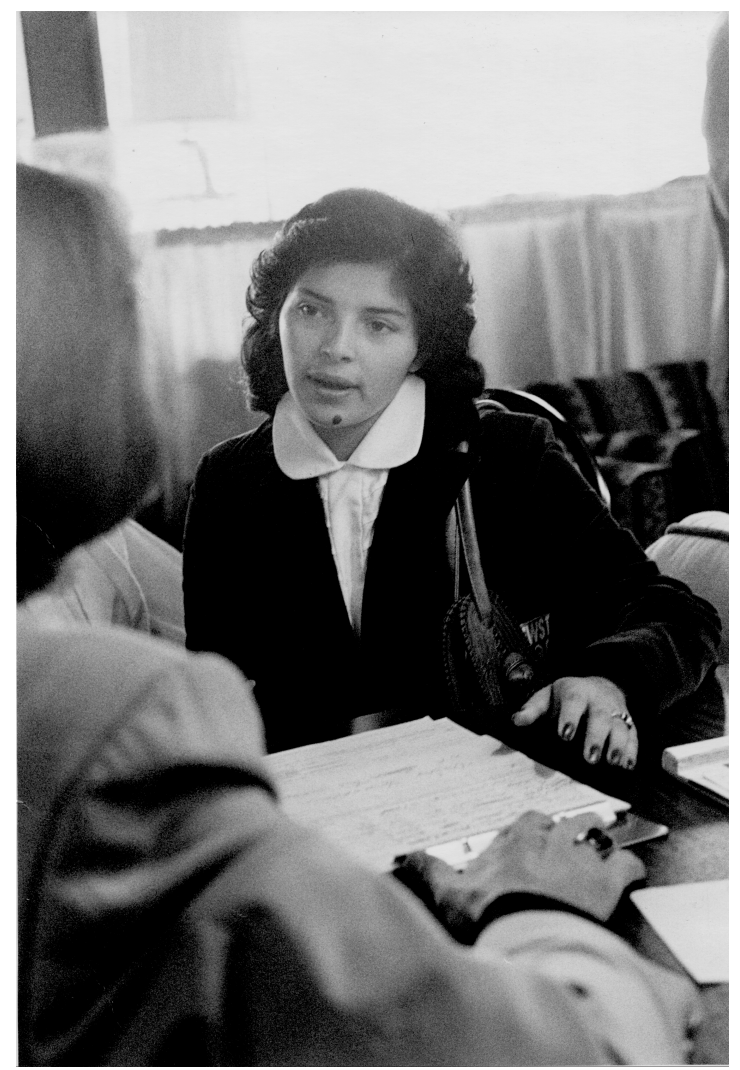

Fig. 1. Irene (Vilma Coronado) en Después del Terremoto

Así, por lo menos ideológicamente, la "casa" para las trabajadoras domésticas opera en menor medida como un sitio de trabajo casero (homemaking), y en mayor medida como una extensión de la división del trabajo en el capitalismo. Que es precisamente por lo qué Irene, en Después del terremoto, confronta a Roberto con tanta ambivalencia. La película empieza estableciendo la independencia económica de Irene cuando la muestra comprando una televisión con su propio dinero. Con este acto, la protagonista entra a la esfera del consumo capitalista y se muestra la ilusión de libertad que se da a través del consumo. Al final de la película, 
los espectadores están también conscientes de que el matrimonio con Roberto reduciría este tipo de libertad ya que para la cultura latina tradicional, el hombre es quien debe manejar los ingresos de la mujer. Es más, la subordinación de Irene a través de matrimonio abarcaría otras dimensiones de su vida, particularmente en términos del ámbito doméstico. Además del cambio experimentado por las madres y las esposas que trabajan, las trabajadoras domésticas latinas enfrentan un "doblejornada" en la medida en que se ven obligadas a realizar un mismo tipo de trabajo, tanto dentro como fuera de la casa. Uno es pagado y el otro no, pero ambos, de cualquier manera, son trabajos domésticos. De varias maneras, la ambivalencia de Irene hacia el matrimonio cuestiona, precisamente, el mito de la domesticidad y del rol de "guardianes del hogar y de lo doméstico".

Sin embargo, de esta manera las realizadoras plantearon la cuestión de las políticas del género desde el punto de vista de una inmigrante latina a través de la dinámica entre dos sistemas culturales, visualizando el discurso informal de una conciencia del contrapeso que resulta de la experiencia cotidiana de la opresión de una mujer. A través de una narrativa realista, las realizadoras plantean la opresión de la mujer explorando los movimientos identitarios de una inmigrante latina, así como los significados que en ese contexto para ella tiene el ser mujer. Después del terremoto presenta a una mujer que es consciente de las estructuras sexuales, de género y culturales que la han formado pero que al mismo tiempo, y de manera firme y deliberada, decide romper con ellas.

Y aunque el punto principal de la película es la política de género --los conflictos y diferencias dentro de la comunidad inmigrante nicaragüense-las realizadoras retratan varios de los procesos sociales, incluyendo las condiciones del exilio, la ruptura, la migración transnacional y identidad bicultural, y la intersección entre las identidades de clase, nación, étnia. Además la película plantea el fenómeno llamado "feminización de la migración laboral, que alude al incremento del número de mujeres trabajadoras que cruzan las fronteras nacionales.

\section{Reinventando la maternidad}

Como en Después del terremoto, el internacionalismo de Portillo se filtró a través de las lentes de la política del género en el film Las Madres: The Mothers of the Plaza de Mayo (codirigido por Susana Muñoz). Se trata de un documental sobre las madres de los "desaparecidos" en Argentina. En contraste con Después del terremoto, Portillo optó en esta ocasión por el documental político para contar la historia de las luchas de oposición de las mujeres:

Pense que antes que nada, cuando se hace una película política, se debe de sentir nuestro interior. Con la historia de "madres"... parece que no había otra manera de contar su historia, tratamos de imaginarnos otra forma, pero 
parecía que ésta era la única vía de aproximarnos a Las Madres. Con la problemática de Nicaragua, [la historia] podía manejarse más, pero el drama inherente a Las Madres sólo nos permitió hacerlo de esa manera (Newman y Rich, 1990: 66).

Y era de hecho un poderoso drama que describía el desarrollo de la "guerra sucia” del régimen militar a través de perspectiva de los habitantes de esa nación; un drama que muestra a la junta militar que gobernó Argentina de 1976 a 1983 y que fue responsable de la desaparición de 11 mil argentinos; un drama que se centra en un grupo de madres que desafían a la brutal junta militar al realizar manifestaciones y plantones ilegales en la más protegida de las plazas públicas de Argentina, la Plaza de Mayo, retando de manera directa a la autoridad del Estado. Las cineastas reconstruyeron el drama de su sufrimiento con intensidad cinematográfica. Mezclaron estrategias realistas como la entrevista con imágenes de archivo y voz en off de tal forma que Las Madres remarca la lucha de las mujeres contra un régimen violento, represivo y da voz a una forma femenina de resistencia del histórico rol social asignado a las mujeres: la maternidad.

Como sabemos la "maternidad" es la forma tradicional a través de la cual el Estados moderno produce mujeres como sujetos de la nación a los cuales se les reafirma su rol como reproductora confinándolas de esta manera a la esfera privada y doméstica del cuidado de los niños. Aún así, es desde su ubicación social como "madres" que las mujeres argentinas organizaron su intrépido desafío, actuando en la esfera pública en un momento en el que la mayoría de las personas, incluso los medios de comunicación, permanecieron indiferente a la "guerra sucia" del régimen militar. A pesar de que este régimen respondió violentamente contra estas madres, arrestándolos y incluso desapareciendo a algunas de sus fundadoras como Azucena De Vicenti (la creadora de la idea de las demostraciones en la Plaza), dos monjas francesas y una artista, las Madres de la Plaza de Mayo continuaron con sus manifestaciones y demostraciones cubriéndose la cabeza con su tradicional pañoleta blanca ${ }^{3}$.

De manera meticulosa las realizadoras muestran como las mujeres, como las madres de los desaparecidos, pueden redefinir y reapropiarse la maternidad como un modelo de resistencia que unifique a las mujeres de distintos sectores sociales frente a su lucha contra la represión del nacionalismo patriarcal. La narrativa de Las Madres enfatiza los procesos de radicalización, y no de victimización, de tal forma que puede inspirar a los auditorios de todo el mundo. De manera muy eficaz aborda el tema de la toma de conciencia política y de radicalización de un grupo de mujeres de mediana edad a partir de su dolor personal como madres. Durante el proceso de exigir la aparición de sus hijos en las calles de Argentina, estas mujeres

3 Ver Simpson y Bennett (1985), especialmente las páginas 155-170. 
transformaron ese aspecto privado de la identidad de género: la maternidad, en una identidad política que operaba en la esfera pública de la nación. Como la vicepresidenta de las Madres, Adela Antokaletz, expresó: "Nosotros decidimos tomar a las calles, y fueron las calles que nos enseñaron... Y eso fue lo que nos dio nuestra fuerza política”. El documental termina el drama de la oposición y resistencia de las mujeres con un collage de imágenes de madres de otras partes del mundo que enfrentan también la luchas en contra de la desaparición de sus hijos.

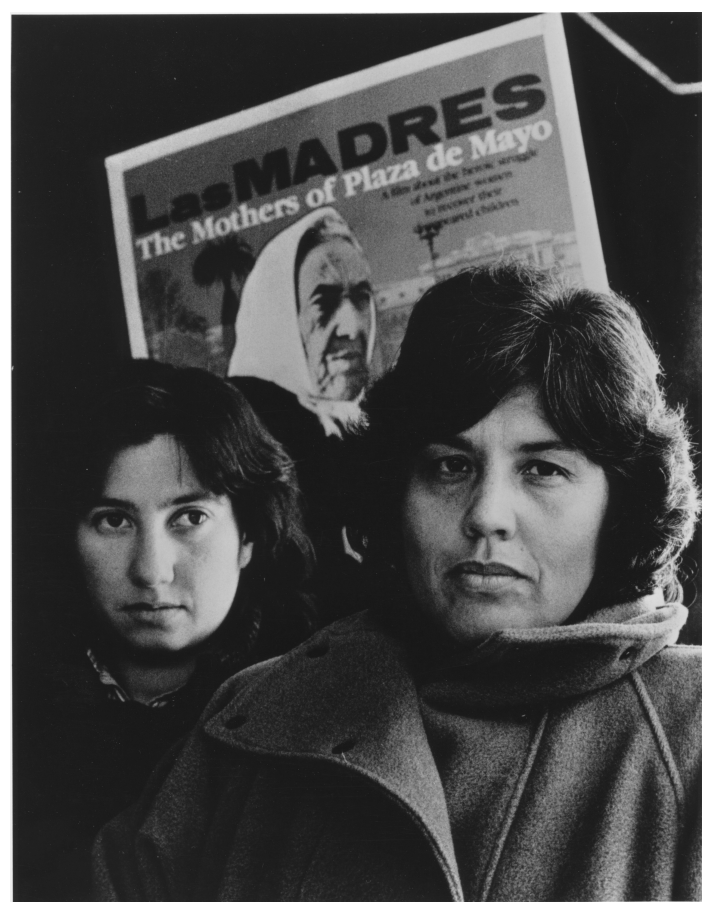

Fig. 2. Susana Blaunstein Muñoz y Lourdes Portillo.

En los primeros años de la transición democrática, el nuevo gobierno capituló a los gobernantes militares anteriores, descuidando las preocupaciones de las Madres. Frente al descontento y a la desilusión de las Madres de la Plaza de Mayo, en 1990 el Presidente Carlos Menem perdonó a los miembros de la junta militar, incluyendo su cabeza, el general Jorge Videla. Aunque la amnistía fue justificada como un gesto de conciliación nacional ("la decisión de perdonar a los dictadores por el interés de paz"), en realidad fue diseñada para aplacar a las fuerzas derechistas de la nación y también como un mecanismo que les permitiera a los argentinos olvidar o negar la obsesionante presencia de los desaparecidos. Pero los fantasmas tienen muchas maneras de regresar y frecuentar a los que viven. Mientras el gobierno argentino perdonó crímenes como la muerte y la desaparición, los

4 Citado en Simpson y Bennett, 169. 
crímenes contra los niños de los desaparecieron no fueron cubiertos por la amnistía. Así en julio de 1998, Jorge Videla, general jubilado, fue juzgado por su rol en el robo de a los hijos de las prisioneras embarazadas, es decir, de las "desaparecidas," y se les dio en adopción a funcionarios y amigos del ejército ${ }^{5}$. Parece que los fantasmas de los desaparecidos regresaron para reivindicar las demandas sobre secuestro de las Madres --testimonios que se articulan elocuentemente en el documental de Portillo y Muñoz, Las Madres: The Mothers of the Plaza de Mayo.

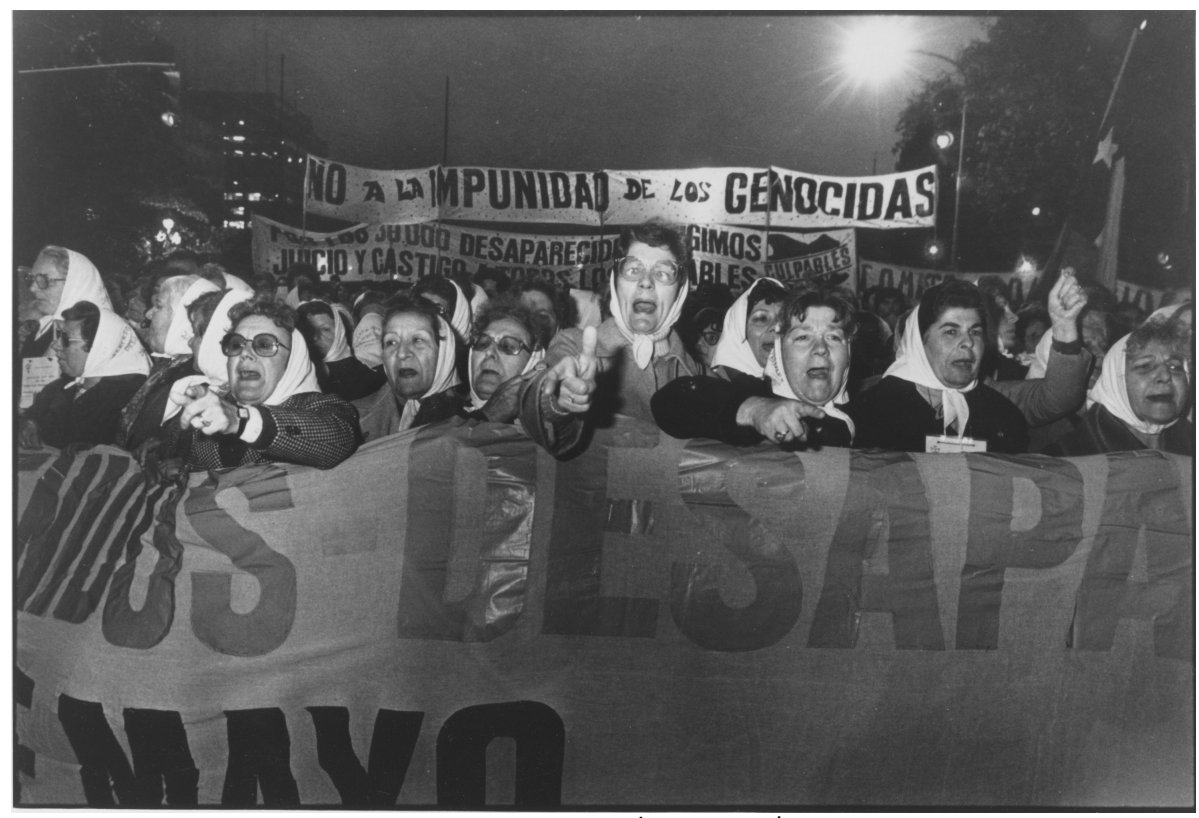

Fig. 3. Escena de Las Madres

\section{Migraciones globales y continuidad/discontinuidad cultural}

Portillo colaboró con Muñoz en otro proyecto más, de nuevo abordando aspectos complejos sobre el contacto entre las distintas comunidades de América. En esta ocasión, Portillo decidió volver a su propia cultura tocando un tema que le permitía sanar el dolor del anterior. Como la misma Lourdes Portillo expresó:

Las Madres me hizo sentirme tan mal que quise sentirme bien y para ello (le dije a Susana Muñoz) 'quiero pensar en la muerte de la forma en que mi gente piensan en la muerte, no de la manera en la que ustedes piensan en la muerte'. La Ofrenda fue la reacción a Las Madres (Newman y Rich, 1990: 66).

La película La Ofrenda, traza las continuidades y discontinuidades en prácticas culturales que cruzan la frontera México-Estados Unidos. El film empieza

5 Ver Faiola (1998). 
en México, contando la historia, las prácticas culturales y los rituales asociados con la celebración del Día de Muertos que tiene lugar cada año los días 1 y 2 de noviembre. Se trata de una festividad iniciada antes de la conquista de México pero que continúa como una tradición cultural vital. La segunda mitad de la película alude a las formas en las que el Movimiento Cultural Chicano revivió estas prácticas en el contexto de San Francisco (California) durante los años setenta. En esta parte del documental se muestra la forma y el sentido que tiene para los chicanos que viven en la colonia de la Misión.

A pesar de que la celebración del Día de Muertos unifica la narrativa del documental, los significados y rituales asociados con la celebración difieren en cada contexto. En Oaxaca, la película retrata el Día de Muertos como algo vinculado orgánicamente a un estilo de vida y a una comunidad movilizada para la festividad: desde cocinar las comidas tradicionales, vender y comprar los artículos necesarios en la plaza, la elaboración de calaveras por parte de los artesanos, el rezo de los devotos frente a los altares, hasta la visita a la tumbas de los muertos para limpiarlas, adornarlas y comer celebrando a sus muertos. De esta manera, para los indígenas de Oaxaca, el Día de Muertos forma una parte integral de las tradiciones comunitarias, así como de sus prácticas espirituales, culturales y materiales cotidianas.

En California, en cambio, la celebración del Día de Muertos resuena con cierta nostalgia. La Ofrenda devuelve la memoria cultural de una festividad que está descontextualizada, o menos localizada en la vida cotidiana de quienes la celebran y que se vive entre objetos, como los altares domésticos y fotografías, así como en ámbitos institucionales a través de demostraciones más espectaculares como son los desfiles y las exposiciones artísticas en museos, escuelas, universidades y centros culturales. En la visualización del contraste entre Oaxaca y California, las realizadoras enseñan a su auditorio un importante aspecto de los procesos de hibridismo cultural y transculturación. Por ejemplo, la película muestra a la cultura de una manera muy dinámica, las realizadoras se negaron a fetichizar a la cultura como un objeto estático, que se pasa de generación en generación y en diferentes espacios geo-políticos pero sin alterarse. Por el contrario, el documental presenta a la cultura y a las tradiciones culturales como prácticas activas, vividas y dinámicas. Al partir los migrantes de su tierra, se llevan con ellos sus tradiciones culturales, pero estas, especialmente las de los migrantes transnacionales, no permanecen intactas sino que se ven afectadas por procesos de ruptura y dislocación que a su vez las modifican, transforman e incluso, reinventan. La película nos lleva a ese universo de cambio cultural, mostrando a una comunidad méxico-americana que responde creativamente a presiones ambientales y sociales reconstruyendo tradiciones culturales en un nuevo contexto. 
Al trazar las continuidades y discontinuidades de prácticas culturales que cruzan la frontera México-Estados Unidos, La Ofrenda hace evidente adicionalmente, cómo estos procesos son particularmente agudos cuando se trata de comunidades inmigrantes que deben adaptarse a las diferentes circunstancias del país al que llegan, y que en general se muestra hostil hacia la diferencia cultural. Y es justamente por eso que el Día de Muerto para los chicanos/as en Estados Unidos responde a necesidades diferentes de aquéllos que la celebran en México. Frente a un gobierno que hostiliza y les niega a los latinos su pertenencia a la nación estadounidense y que viola sus derechos humanos, la celebración del Día de Muertos en Estados Unidos tiene una función política de oposición y de afirmación cultural, en particular de las identidades culturales latinas, y en general de la diferencia multicultural.

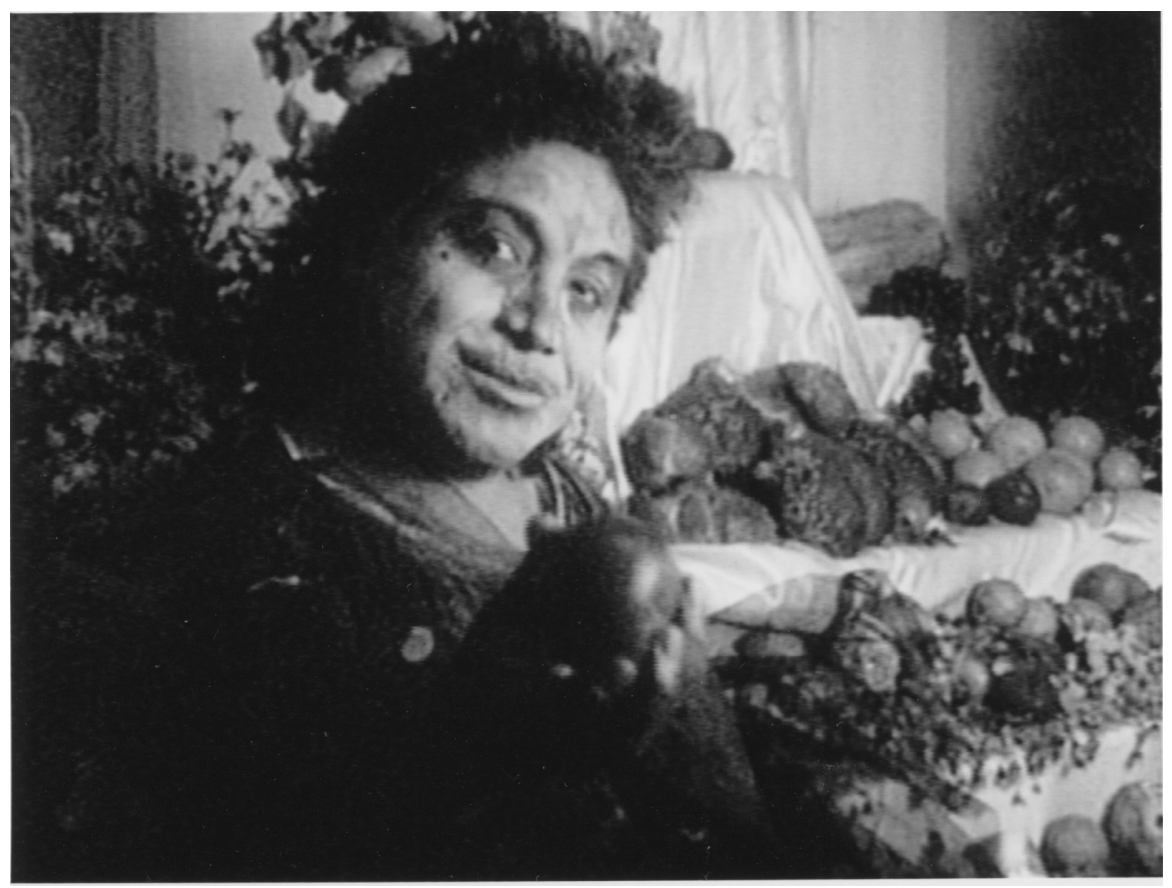

Fig. 4. Escena de La Ofrenda

Dado que la película se estrenó a finales de los ochenta, tuvo la oportunidad de mostrarse de manera regular a través de los canales del Sistema de Televisión Pública (PBS) de los Estados Unidos, por lo que ha sido vista por un público muy amplio y variado. Además, La Ofrenda también ha servido a la comunidad gaylatina en sus esfuerzos para confrontar la epidemia de SIDA, particularmente porque la película abre un espacio para entender formas específicas de confrontación de la muerte a través de rituales culturales. Así como La Ofrenda resultó "curativa" y 
“reconfortante” para Lourdes Portillo, la película, o más bien, la celebración del Día de Muertos, tuvo el mismo sentido para la comunidad gay latina porque ayudó a sanar espiritualmente la pérdida de muchos de sus miembros. De hecho, la película mostró el compromiso con la problemática del SIDA que has abordado los cineastas y videoastas latinos(as). Según la directora latina, Frances NegrónMuntaner, el final de los ochenta se observó un "marcado aumento de los trabajos de homosexuales y lesbianas" como una respuesta a "las transformaciones provocadas por la epidemia del SIDA, además, agrega esta directora, "la crisis del SIDA creó una necesidad política y discursiva para discutir sobre el heterosexismo y promover prácticas sexuales seguras en las comunidades latinas de todos el país (incluyendo aquellas que no se autoreconocen como 'gay'o lesbianas)" (1996: 62).

\section{Desestabilizando el régimen nacional familiar}

Las andanzas documentales de Portillo sobre la frontera dan un giro hacia el documental lírico-subjetivo con El diablo nunca duerme. Una película que cuenta la historia de la investigación que lleva a cabo la cineasta sobre la muerte de su querido Tio Oscar que muere en circunstancias un tanto misteriosas en México. El diablo nunca duerme también hace un boceto de la permeabilidad de las fronteras entre las naciones, los géneros y las identidades politicas/familiares. Esta vez, Portillo cruza la frontera para indagar la muerte, no acalarada, de su tío Oscar Ruíz Almeida, utilizando su vida para tejer las hebras de su investigación. Oficialmente se declara que su muerte fue resultado del suicidio, sin embargo, algunos familiares y amigos sospechan que se trata de un asesinato. En el proceso de investigación, Portillo cruza los secretos familiares, los descubre y presenta a través de los testimonios de familiares y amigos, encontrando con sorpresa múltiples contradicciones en la vida de su tío favorito. De esta manera, el tema de la película sirve de artimaña para entrar al campo de la política y sus secretos, pero no sólo en el campo familiar/doméstico/privado (representado por la problemática familiar de Portillo), sino también a la esfera pública/nacional, personificada por el partidofamilia en el poder, el PRI. Asumiéndose como sobrina-detective-documentalista, Lourdes Portillo narra la historia mostrando y haciendo uso de la intriga, la decepción, la hipocresía, así como también los valores culturales como "el honor", "la lealtad," y "la familia" poniendo en primer plano la compleja problemática de la "familia" chicana y mexicana.

Portillo es una chicana católica que transgrede los límites entre lo público y lo privado, y que presenta y deja que el auditorio haga su propio juicio sobre las verdades y falsedades que hay detrás del velo de los secretos familiares ${ }^{6}$. La cineasta viola el tabú cultural que prohibe el hacer público los asuntos familiares --un tabú

6 Ver Fregoso (1999). 
tan sagrado que incluso permea las estructuras políticas mexicanas - Es decir, se trata de un tabú cultural que circula y se aplica en la arena política y que se conoce como "la mordaza". Dentro del partido en el poder (PRI) existe una especie de órden para no hablar de los problemas de la "familia-partido" y especialmente de los presidentes anteriores pertenecientes a esta familia. De esta forma se ve como el aparato político del PRI está basado en el modelo de "familia, y Portillo logra entrar al reino de los asuntos familiares para dejar ver, entre otras cosas, el patriarcado mexicano.

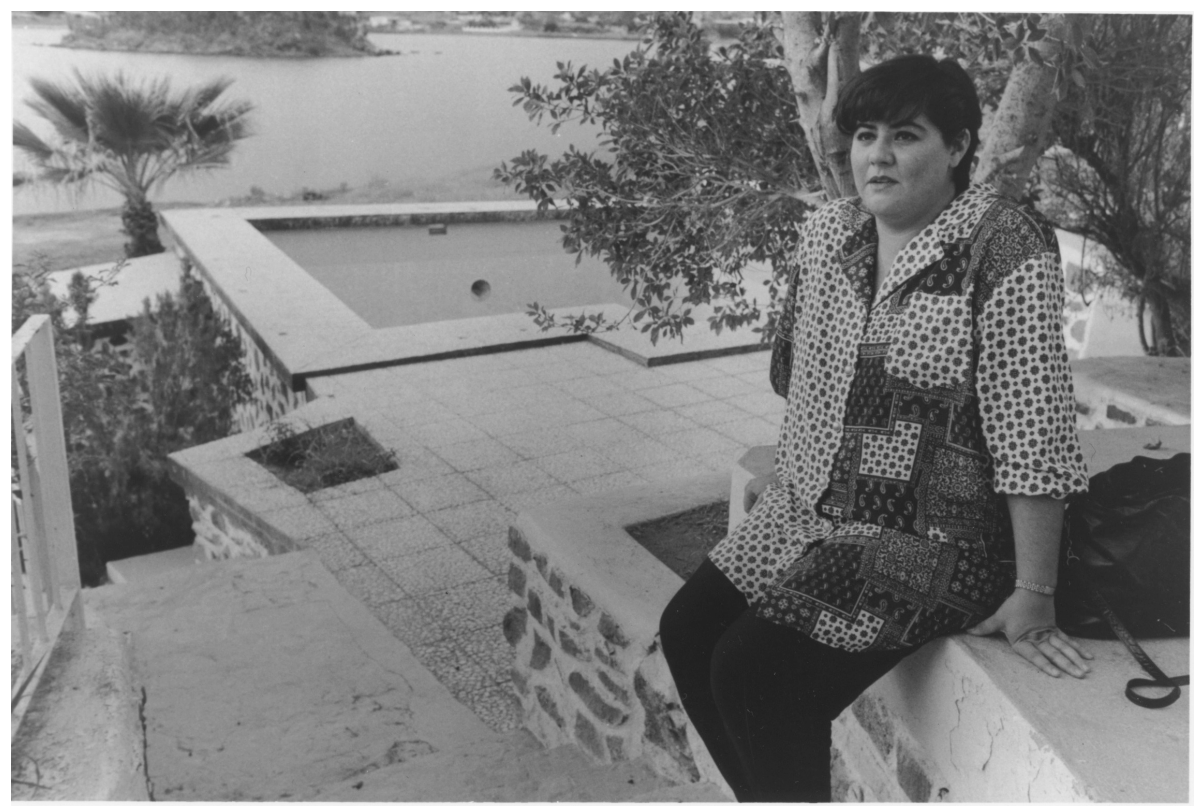

Fig. 5. La hija de Tio Oscar, El diablo nunca duerme

Al transgredir el pacto de respeto a los asuntos familiares como asuntos únicamente privados, El diablo nunca duerme diluye la distinción entre los privado y lo público, y se une así a la preocupación feminista sobre 'la familia' como un elemento clave de las relaciones de poder, y como una forma de dominación en las microestructuras de la vida cotidiana. Al darle su ubicación sólo en la esfera doméstica, 'la familia' juega un papel fundamental en el mantenimiento de la ley del padre y la subyugación de las mujeres. Las críticas feministas norteamericanas ha defendido que la naturalización de los privilegios masculinos y su hegemonía, se ha derivado de la fuerza para defender la noción idealizada de la comunidad monolítica y el romance familiar. Con el fin de entender la importancia de este trabajo de Portillo dentro del discurso de feminismo chicano, se debe entender el rol central que juegan los valores familiares en la política del nacionalismo chicano.

Portillo rompe el silencio alrededor de la unidad familiar tan enraizado en los mexicanos y en nacionalismo chicano, y deconstruye los valores asociados con la 
familia chicana y mexicana, incluyendo los mitos de "la solidaridad familiar, del compadrazgo y la confianza" (Segura y Pierce, 1993: 72). Desde el Movimiento Chicano de los sesenta, el nacionalismo chicano ha convertido a la familia en el fundamento de su política de oposición, y se insiste en la representación de esta como única y coherente, siempre heterosexual y nuclear. Guiada por la narrativa nacionalista mexicana del $\mathrm{amo}^{7}$, la familia aparece como el ejemplo máximo de la "lealtad de la comunidad". Hablar en contra del sexismo y del abuso perpetrado por los varones chicanos equivale a violar la confianza de la comunidad, a romper los elementos emocionales de la solidaridad familiar, lo que significa entonces la traición a la familia. Los mecanismos de reproducción de este discurso nacionalista sobre la lealtad de la comunidad se localizan en la división estricta entre las esferas privadas y públicas y enmarca la fantasía nacionalista sobre la familia como el santuario interior que los protege de las amenazas externas.

El sólo hecho de centrarse en la normatividad de los atributos de la solidaridad familiar y la confianza, hace que El diablo nunca duerme sirva como un instrumento de crítica al nacionalismo chicano, ya que estos atributos son sus pilares y le sirven para consolidar las mitologías familiares, borrar sus contradicciones, y naturalizar el privilegio masculino. Tomando a su tío favorito como sujeto de estudio, Portillo cuestiona los principios chicanos como son: la noción entrelazada de familia y comunidad, la artificial división entre las esferas públicas y privadas, y la idea de la familia como institución sagrada. Portillo simultáneamente se posesiona dentro y fuera de la familia, y ahí la libera de sus propios secretos al hacerlos públicos, la expone, no como la familia sagrada, bendita, intocable y santa (que promueve el catolicismo) sino como la familia que es escenario de conflicto y enfrentamientos.

La importancia de la intervención de Portillo va más allá de los aspectos narrativos o temáticos de película. Como se mencionó anteriormente El diablo nunca duerme entra al espacio del imaginario poético porque Portillo insiste en moverse lejos de la exactitud, la realidad y la autenticidad para lograr la verdad narrativa. La estructura formal de esta película simultáneamente reconoce y crítica las convenciones del cine documental para que Portillo, de manera autocrítica y consciente, las utilice como estrategias realistas.

Portillo cuestiona los criterios de verdad y exactitud del documental, así como la certeza de la evidencia al presentar una verdad plural y al dibujar la parcialidad y la naturaleza construida de las imágenes. La realizadora recurre a las técnicas reconocidas del documental tradicional (como son la entrevista, imágenes de archivo, fotos familiares, la voz de un narrador) pero no es más verdadera la versión del "meta-discursivo" del propio documental, ni tampoco alguna de las varias

7 Ver Franco (1986). 
versión sobre la muerte del Tio Oscar. Todos los puntos de vista de los entrevistados, las digresiones del narrador, el material de archivo, los materiales caseros, tienen tanta validez como cualquiera de los otros.

Portillo se niega a constituir un discurso único basado en su interpretación como documentalista, y en cambio formula una pluralidad de versiones. La estratégica de sobreposición de múltiples formas de representación (derivados de géneros distintos) hace evidente su negativa para privilegiar el documental como la única manera de interpretar y aprehender la realidad. Y mientras la película reconstruye su pluralidad a partir del montaje de técnicas modernas para la recolección y clasificación de información documental (la entrevista, imágenes de archivo, películas y fotografías caseras, narración), la documentalista hace problemático el estatus de discurso documental "oficial" al presentar otras formas culturales especificas de conocimiento asociadas con el espacio de lo "popular". Específicamente Portillo, sigue pistas y hechos de fuentes populares de conocimiento y experiencia, es decir, de aquéllos recursos y fuentes que se consideran "descalificados" o "inadecuados" para un documental, como son las leyendas, los chismes, las telenovelas, las canciones rancheras, los mitos, los proverbios, los dichos y los rumores, en suma, de fuentes que según Foucault representaban una forma "particular, local, regional de conocimiento, diferenciable e incapaz de ser unánime” (1980: 82). Estas fuentes de conocimiento son opuestas al proyecto modernista de la certeza, la uniformidad, la verdad absoluta, asociadas a los discursos documentales "oficiales", ya que los conocimientos populares se interpretan como parciales, contradictorios, ambivalentes y en una relación conflictiva con la interpretación dominante y singular de la realidad social. Portillo se da a la tarea de buscar la "verdad" sobre la muerte de Tío Oscar yuxtaponiendo las formas "populares" y "oficiales" de conocimiento, y negándose a privilegiar cualquiera de ellas.

En un estilo que cita, parodia y deconstruye los tradicionales documentales de la televisión pública norteamericana (PBS), El diablo nunca duerme argumenta en contra de la certeza de la realidad documental, rechazando también su sentido de cierre y de integridad. Al hacer esto, la película hace que los espectadores sean conscientes de la naturaleza 'manipuladora' del cine, en particular del documental realista, especialmente en la escena en donde inserta un enorme tomate cuando habla de la empresa agrícola de Tio Oscar, o cuando la realizadora, proporciona evidencias a través de leyendas, proverbios, parábolas de serpientes y santos, o cuando sugiere normas sociales y de comportamiento a través de movimientos de algunos juguetes. Con estos ejemplos, El diablo nunca duerme permite que el público se de cuenta de que el mismo proceso de producción limita una posición neutral, así como la habilidad para documentar objetivamente. Mientras la película 
en parte confía en las estrategias realistas, también contribuye un vocabulario crítico que ha empujado a muchas realizadoras del cine documental realista de los noventa hacia una "práctica de autoconciencia teórico/política" (Juhasz, 1994: 177) y hacia el documental lírico-subjetivo. De esta manera, al jugar con los límites de realismo documental, Portillo contribuye a la evolución de este género cinematográfico.

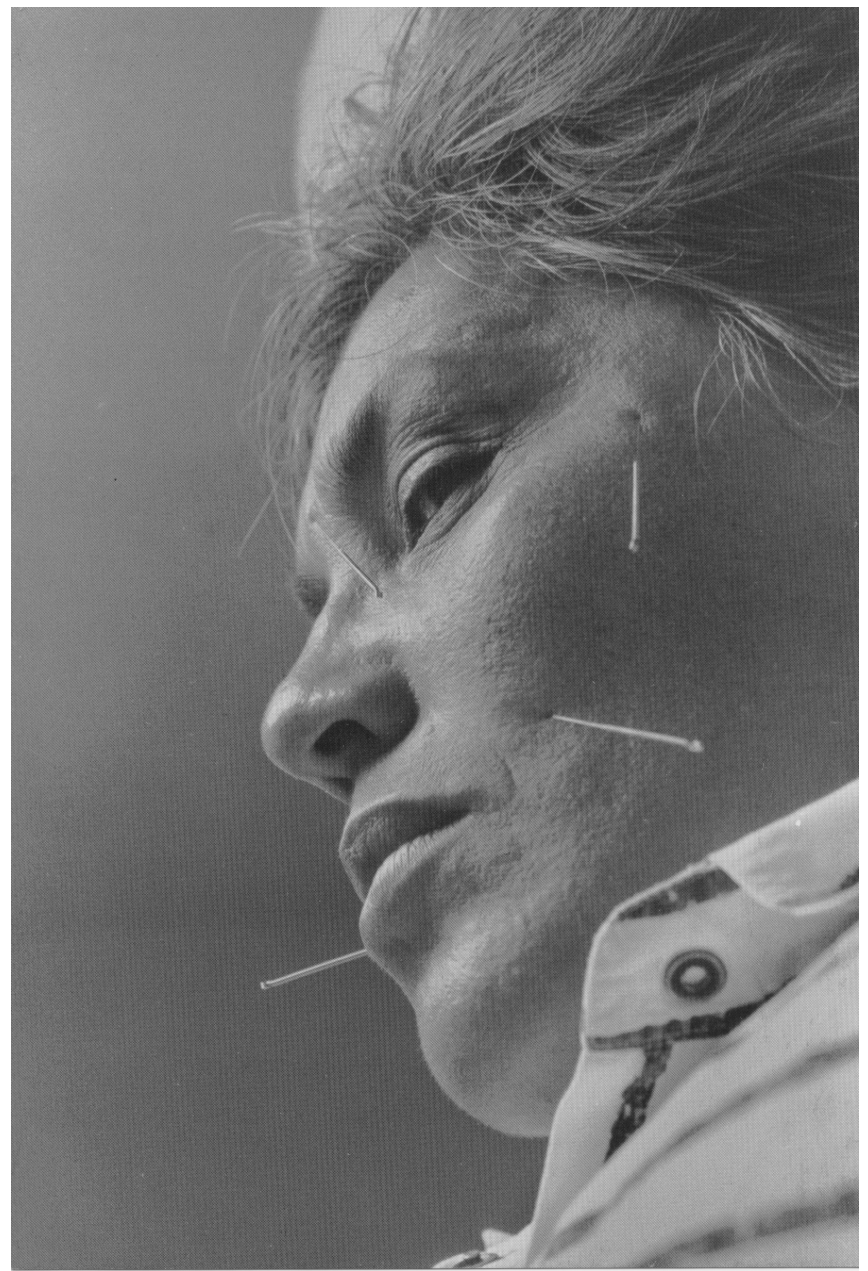

Fig. 6. Lourdes Portillo en El diablo nunca duerme

\section{Transformando el terror $^{8}$}

Su último documental Señorita Extraviada está impulsado por una poética política y una ética destinadas a la transformación del terror. El documental investiga lo que en un tiempo se consideró el problema principal de los derechos humanos en México: el asesinato y la desaparición de cientos de mujeres y niñas en la ciudad fronteriza, asolada por la violencia, de Ciudad Juárez, que data de 1993

8 Partes de esta sección fueron traducidas por Graciela Trevisan. 
(Fregoso y Bejarano, 2011). En el momento del estreno del documental en 2001, cerca de 300 mujeres y niñas habían sido asesinadas, aproximadamente una tercera parte en circunstancias similares: se las mantuvo en cautiverio y fueron sometidas a formas extremas de violencia sexual, violación, tortura, estrangulamiento, y también ahorcadas y quemadas; sus cuerpos, arrojados en zonas remotas y escasamente pobladas de la ciudad. Al describir estas atrocidades, Portillo se esfuerza por transformar las mismas condiciones que dieron origen a estos actos inhumanos en primer lugar. La poética política del documental fomenta entendimiento y compasión por las víctimas y sobrevivientes de las violaciones de los derechos humanos. Portillo ha subrayado: "Nuestra tarea consiste en comunicar de corazón a corazón, unir nuestras fuerzas para poner fin a la violencia y la brutalidad perpetuadas sobre las que no tienen voz".

Aunque el impacto real de Señorita Extraviada sea difícil de determinar, el documental de Lourdes Portillo está sobretodo impulsado por el deseo de cambiar los corazones y las mentes de las espectadoras y los espectadores. "Toda la intención de la película era crear una especie de conciencia, incitar a la gente a actuar, y éso es lo que hizo" (Portillo, 2003: 231). Portillo se convirtió en una defensora de los derechos humanos de las mujeres, exhibiendo la película ante públicos internacionales y creando conciencia sobre la persistencia de la violencia feminicida en México.

Señorita Extraviada se ha exhibido a miembros de órganos estatales e intergubernamentales, como el Parlamento Europeo, el Congreso de los Estados Unidos y la Corte Penal Internacional, así también como en conferencias y foros de derechos humanos como la 9a. Cumbre Mundial de Premios Nobel de la Paz en París. La película ha ganado más de veinte premios en los principales festivales nacionales e internacionales de cine, incluyendo el Premio del Jurado al Documental en el Festival de Cine de Sundance, el "Premio a una/un Artista", otorgado por primera vez por Amnistía Internacional, el "Premio Nestor Almendros" otorgado por Human Rights Watch, el premio al mejor documental en el Festival de Cine de La Habana y el "Premio FIPRESCI" en el Festival de Cine Documental de Salónica. Portillo ha realizado giras con el documental más allá del circuito de festivales, mostrando la película a grupos organizadores y de activistas en América Latina, los Estados Unidos y Europa.

Esta visibilidad pública y reconocimiento le han dado a la directora una plataforma para dar testimonio de las injusticias cometidas contra los derechos humanos en la frontera y denunciar al gobierno de México por su complicidad en el terror a las mujeres. Señorita Extraviada informa a las espectadoras y los espectadores sobre el tema de la violencia feminicida en Ciudad Juárez, pero va más allá del nivel informativo. Incita la imaginación e inspira la participación creativa. 
"Asi que ésa fue realmente toda la intención de la película”, explica Portillo. "Crear una especie de conciencia, incitar a la gente a actuar, y éso es lo que hizo. Pienso que cada vez que la película fue mostrada en algún lugar, la gente se indignó, como debería ser. En todos los lugares adonde iba, la gente quería saber ¿¿Qué puedo hacer?' Fue entonces en ese momento cuando dije: 'sí, tengo que pensar qué pueden hacer'. Y necesito tener direcciones y necesito tener personas con quienes se puedan conectar y cosas para hacer. En todos los lugares adonde iba, siempre era lo mismo, ¿sabes? La gente quería saber algo, en todas partes. Nunca hubo una proyección del documental sin que alguien se parara y dijera: 'voy a escribir una carta al consulado de México'. Era increíble. Recuerdo en Quito, Ecuador, mostré la película y un señor de edad, de alrededor de ochenta años, se paró y dijo: 'Bueno, estoy indignado y creo que esto es una vergüenza, es una vergüenza para el gobierno de México y hoy cuando vuelva a casa voy a escribir una carta al embajador de México. ¿Y quién en esta audiencia', preguntó a alrededor de doscientas personas, 'va a escribir una carta como la mía?'. Y todas las personas levantaron la mano. Fue tan conmovedor, tan hermoso que la gente sintiera ese tipo de compasión por las niñas, y estuviera dispuesta a hacer algo" (Fregoso, 2003).

Este efecto increíble de motivar a las espectadoras y los espectadores a la acción es la marca más alta de logro para una documentalista política como Portillo, o para el caso, para cualquier movimiento de arte político, como el del nuevo cine latinoamericano, cuyo "denominador común" es como mencioné anteriormente "una poética de la transformación de la realidad". Las estrategias discursivas y estéticas detrás de una poética de transformación social incluyen la responsabilidad de las y los artistas e intelectuales en dar testimonio del terrorismo de estado y en nombre de personas que sufren persecución y violación de sus derechos humanos. Esta urgencia ética de dar testimonio en nombre de las muertas y desaparecidas de Ciudad Juárez recuerda a la tradición latinoamericana del testimonio cuyo proposito es motivar a sus audiencia a la acción. Como explica Cubileé en el contexto de la obra "La escuelita" de Alicia Partnoy: No es permitido que la posición de "espectador distante" sea por defecto, la posición 'no marcada', porque al contrario, es marcada como la posición del que niega la humanidad completa a los muertos y sobrevivientes de la atrocidad" (2005: 187).

Señorita Extraviada es un documental que perturba el espacio del espectador distanciado. La demanda que hace Portillo es similar a la de Judith Butler, que hace un llamado "a un nuevo modo público de ver y escuchar, que pueda responder al llanto de lo humano dentro de la esfera de la apariencia” (2006: 44-5). El documental insiste en que escuchemos y reconozcamos el "llanto de lo humano" en nuestro reconocimiento de la humanidad de "las mujeres que han sido (y continuan siendo) sacrificadas", como explica Portillo, por el simple hecho "de ser 
consideradas como mujeres sin valor. Son pobres, son morenas, son todo lo que no tiene valor en México, ellas lo personifican” (Fregoso, 2007).

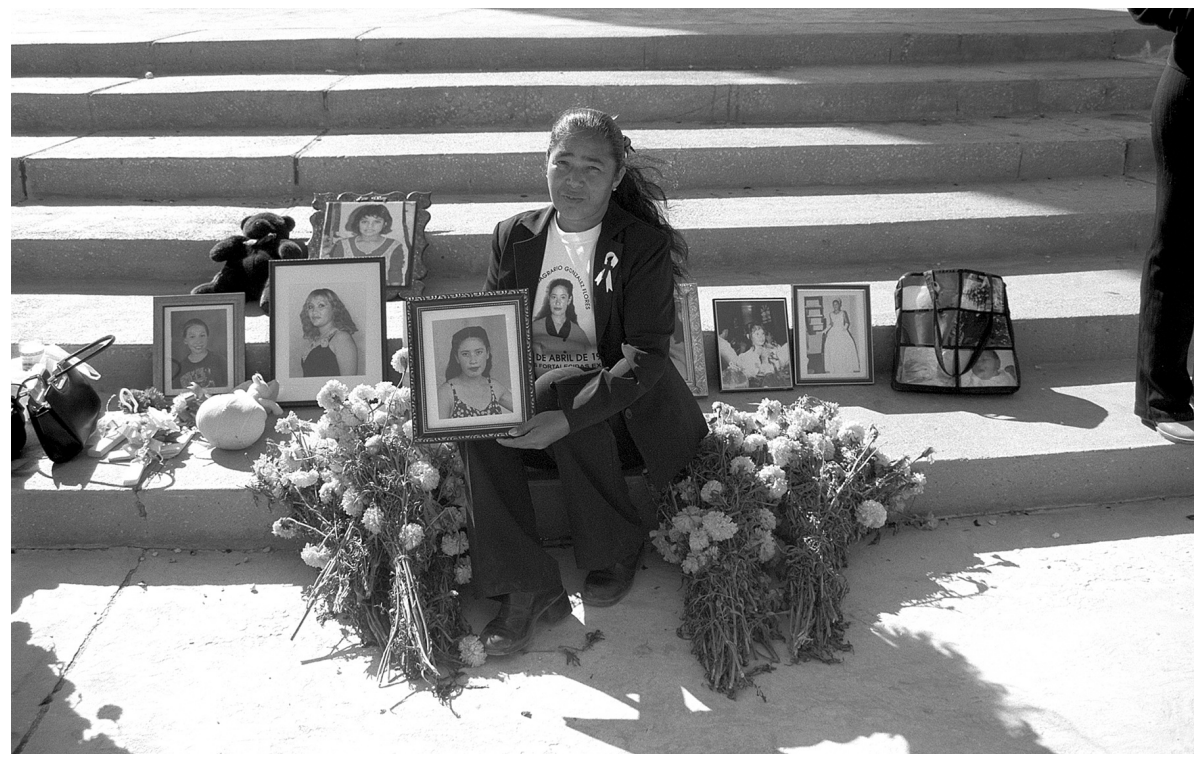

Fig. 7. Paula Flores, madre de Sagrario, Señorita Extraviada

En su reconocimiento de la humanidad y del "llanto de lo humano", Portillo reaparece a las muertas y desaparecidas, de ese espacio profundamente escondido que el estado mexicano ha generado cuando niega e invisibiliza al feminicidio. Señorita Extraviada reconoce la violencia feminicida tanto como testigo en contra de la vida misma, como en contra de una identidad feminina particular: mujer menospreciada por clase y raza/étnia.

\section{A manera de conclusión}

A través de estas líneas he evaluado críticamente las contribuciones de Lourdes Portillo al cine feminista descolonial de nuestra época de grandes tranformaciones socioeconómicas a nivel global. Una mirada general de sus películas y videos confirma hasta que punto la firma de Portillo como cineastas se fija sólidamente en el "reino imaginativo," en un estilo poético-meditativo que es más 'contemplativo' que simplemente 'informativo'. Como Las madres: The Mothers of the Plaza de Mayo, La Ofrenda: the Days of the Dead y El diablo nunca duerme lo hacen evidente, Portillo mezcla en la narrativa de sus películas las estrategias realistas con un estilo imaginativo típico de la ficción. Sus documentales son narrados en tono lírico, personal e íntimo de una voz lírica-subjetiva que sugiere, y no como la narración del documental clásico que resulta distante y autoritaria ("la voz de Dios"). Su voz femenina, como explica Judith Mayne, "desestabiliza la simetría 
convencional en donde se presume que el registro vocal de la autoridad es masculino, y el dominio de lo visible, femenino" (Mayne, 1990: 51).

A pesar de que su trabajo conforma la estética del cine realista, Portillo ha creado un estilo cinematográfico genuinamente híbrido en la medida en que cruza múltiples fronteras de estilos, y mezcla tradiciones estéticas. En sus trabajos se evidencia la tensión entre la ficción y el documental, así como la influencia de la telenovela latinoamericana, el neorrealismo y cine cubano. Como realizadora, Portillo constantemente ha experimentado en formas y técnicas como lo demostró en El juicio de Colón en donde hace un amplio uso de lo que se conoce como "blue screen" ("pantalla azul"), una técnica comúnmente utilizada en la televisión, particularmente en noticieros e informes meteorológicos, que permite sobreponer imágenes en fondos con movimiento. A pesar de que el "blue screen" hoy en día se usa ampliamente en los documentales independiente, Portillo fue una de las primeras en usar esta técnica en un contexto político, estético.

A pesar de su reconocimiento internacional, Portillo mantiene apasionadamente su independencia, permaneciendo en el borde del dominio comercial Hollywoodense. Y es su libertad e independencia de las reglas del mercado lo que le ha permitido crear y mantener las cualidades subversivas y transgresoras. Estas cualidades y la irreverencia desafiante de sus trabajos han hecho que Portillo sea considerada un modelo de inspiración para los/as cineastas y videoastas más joven. $\mathrm{Su}$ trabajo refleja un amplio rango de preocupaciones, así como la diversidad creciente entre los chicanos/as y latinos/as productores de imágenes alternativas. Tal como lo han hecho otras mujeres artistas, Portillo desestabiliza los cánones y reglas cinematográficas e introduce formas diferentes de abordar la realidad.

Mientras el bloque conservador del Congreso de Estados Unidos limita el uso de fondos públicos para producciones con perspectiva alternativa y de izquierda, el crecimiento de diversos trabajos realizados por mujeres y otros grupos subalternos, muestra que no existen signos de reducción en la producción del arte comprometido. Y no ha habido una marcha atrás porque ya hay una corriente iniciada hace casi medio siglo, en donde las mujeres y otros grupos al margen del poder, entendieron que si se quieren mostrar historias alternativas tienen que documentar sus propias realidades. Su fortaleza y permanencia está también vinculada no sólo al hecho de haber reconocido la necesidad de hacer visible sus realidades, sino también al cuidado de la calidad de sus trabajos, al haber rebasado las fronteras raciales, de clase, culturales y nacionales, y al haber fomentado la alianza y la creación de redes culturales y comunicacionales transnacionales. Por eso el cine y el video feminista "llegaron para quedarse". A pesar de que estamos atrapados por las manifestaciones globales del poder, podemos pensar en la posibilidad del surgimiento de una conciencia planetaria y una política feminista, de redes de 
trabajo y organización internacional, y de formas de hacer cine y video que crucen las fronteras de raza/étnia, nación, cultura, sexualidad y de clase. El legado cinematógrafico de Lourdes Portillo es uno de los mejores ejemplos de la producción cultural de las latinas en los Estados Unidos, que han producido nuevas formas de ver, nuevas lecturas del pasado, nuevas imágenes destinadas a una poética política y ética de un "cine que aspira a modificar la realidad que está siendo proyectada.”

\section{Referencias bibliografías}

Birri, F. (1997). "For a Critical, Realist, National Cinema.” En New Latin American Cinema, Volume 1: Theory, Practices and Transcontinental Articulations, Michael T. Martin, editor. Detroit: Wayne State University Press. pp. 96-101.

Butler, J. (2006). Precious Life: The Power of Mourning and Violence. New York: Verso.

Cubileé, A. (2005). Women Witnessing Terror: Testimony and the Cultural Politics of Human Rights. New York: Fordham University Press.

Davis, A. (1993). Women. Race and Class. New York: Vintage Books.

Faiola, A. (1993, 8 de Julio). "Argentina Dictator Runs out of Pardons," Washington Post. A24.

Foucault, M. (1980). “Introduction.” Herculin Barbin: Being Recently Discovered Memoirs of a Nineteenth Century French Hermaphrodite. New York: Pantheon Press.

Franco, J. (1986). "The Incorporation of Women: A Comparison of North American and Mexican Popular Narrative." Studies in Entertainment: Critical Approaches to Mass Culture. En Modleski, T. editora. Bloomington and Indianapolis: Indiana University Press. Pp. 119-138.

Fregoso, R.L y Bejarano, C. (2011). Feminicidio en América Latina. Mexico D.F.: Centro de Investigaciones de Ciencias Sociales y Humanidades and Universidad Nacional Autónoma de México.

Fregoso, R.L. (1993). The Bronze Screen: Chicana and Chicano Film Culture. Minneapolis: University of Minnesota Press.

- (1999). "Sacando los trapos al sol en Lourdes Portillo's El diablo nunca duerme." En Robin, D. y Jaffe, I. Editores. Women Filmmakers and the Politics of Gender in Third Cinema. New York: Suny Press. Pp. 307-330.

-------- (2003). Entrevista a Lourdes Portillo. No publicada.

-------- (2007). Entrevista a Lourdes Portillo. No publicada. 
Glenn Nakano, E. (1983). 'Racial Ethnic Women’s Labor', Review of Radical Political Economics. Vol. 17. No 3. Pp. 86-108.

Juhasz, A. (1994, verano). "They said we were trying to show reality- all I want to show is my video': The politcs of the realist feminist documentary”, Screen Vol. 35, No 2. pp. 173-191.

Mayne, J. (1990). The Woman At The Key Hole. Bloomington: Indiana University Press.

Negrón-Muntaner, F. (1996). "Drama Queens: Latina Gay and Lesbian Independent Film/Video." En The Ethnic Eye: Latino Media Arts. Noriega, C. y López, A. Editores. Minneapolis: University of Minnesota Press. Pp. 59-78.

Newman, K. y Rich, R. (2001). “Entrevista con Lourdes Portillo, Tijuana, 1990.” En Lourdes Portillo: The Devil Never Sleeps and Other Films, Rosa-Linda Fregoso, editora. Austin: University of Texas Press. Pp. 48-73.

Portillo, L. (2003, otoño). “Filming Señorita Extraviada”, Aztlán Vol. 28, № 2. pp. 229-234.

Romero, M. Maid in the U.S. (1992). New York: Routledge.

Segura, D. y Pierce, J. (1993, otoño). "The Chicana/o Family Structure and Gender Personality, Chodorow, Familism, and Psychoanalytic Sociology Revisited," Signs. No 72. Pp. 62-91.

Simpson, J. y Bennett, J. (1985). The Disappeared and the Mothers of the Plaza. New York: St. Martin's Press. 